\title{
Research Letter \\ Effect of Irradiation Parameters on Morphology of Polishing DF2 (AISI-01) Surface by Nd:YAG Laser
}

\author{
Wei Guo \\ Department of Manufacturing Engineering and Engineering Management, City University of Hong Kong, \\ 83 Tat Chee Avenue, Kowloon Tong, Kowloon, Hong Kong \\ Correspondence should be addressed to Wei Guo, guoweichinese@yahoo.com
}

Received 26 July 2007; Accepted 24 September 2007

Recommended by Jainagesh A. Sekhar

Pulse Nd:YAG laser was used to polish DF2 cold work steel. Influence of irradiation parameters on the 3D surface morphology was studied by 3D profilometer, scanning electron microscopy (SEM), and atomic force microscope (AFM). Results among the tests showed when DF2 specimens were irradiated with parameters of (i) laser input energy $\mathrm{P}=1 \mathrm{~J}$, (ii) pulse feedrate $=300 \mathrm{~mm} / \mathrm{min}$, (iii) pulse duration (PD) $=3$ milliseconds, and (iv) pulse frequency $f=20 \sim 25 \mathrm{~Hz}$; laser polishing of DF2 cold work steel seemed to be successful.

Copyright (C) 2007 Wei Guo. This is an open access article distributed under the Creative Commons Attribution License, which permits unrestricted use, distribution, and reproduction in any medium, provided the original work is properly cited.

\section{INTRODUCTION}

It has been reported that the polishing time of a mould can represent up to $37 \%$ of the total production time of the entire mould [1-3]. Improvement in the finishing or polishing of the mould or die to lessen the input of a skilled operator or to reduce the processing time has the potential to dramatically reduce the cost of the finished item [3-5].

By considering the unique characteristics of the laser radiation and excellent noncontact micromachining possibility with the laser, an attempt has been made to polish DF2 steel employing the concepts of micromachining. Up to now, laser used for polishing metals has been seldom reported. As a powerful surface modification technique, it is imperative to investigate on the laser polishing of metals systematically. This paper mainly aims at investigating the effect of irradiation parameters on the morphology of laser polishing DF2 surface by Nd:YAG laser.

\section{EXPERIMENTAL MATERIAL AND PROCEDURES}

\subsection{Experimental material}

The chemical composition of DF2 cold work steel was C: 0.9, Si: 0.3, Mn: 1.2, Cr: 0.5, W: 0.5, V: 0.1, Fe: Bal. (in wt. \%).

\subsection{Experimental procedures}

The surface roughness of machined materials was $0.2,0.4$, $0.6 \mu \mathrm{m}$. The initial morphology of $0.4 \mu \mathrm{m}$ and its corresponding SEM surface image were shown in Figures 1(a) and 1(b). Figure 1(c) illustrated the microstructure of DF2 steel. A GSI Lumonics Model JK702H Nd:YAG TEM 00 mode laser system, with wavelength of $1.06 \mu \mathrm{m}$, defocused distance of $15 \mathrm{~mm}$, and focus spot diameter of approximately $1.26 \mathrm{~mm}$, was used to irradiate the DF2 steel. After polishing, the surface morphology was observed by Taylor-Hobson Form Talysurf PGI and scanning electron microscope (SEM) JEOL/JSM-5600.

\section{RESULTS AND DISCUSSION}

\subsection{Influence of relative irradiating speed (feedrate) between laser and workpiece}

Although laser-irradiated surface removed most high plateaus from the original surface of the specimens (cf. Figures 1(a) and 2), improper setting of irradiation might roughen surface rather than smoothening it. Laser irradiation with original surface roughness $\mathrm{Ra}=0.4 \mu \mathrm{m}$ under different feedrates with operational conditions of pulse energy $1 \mathrm{~J}$, frequency $25 \mathrm{~Hz}$, and pulse duration 3 milliseconds 


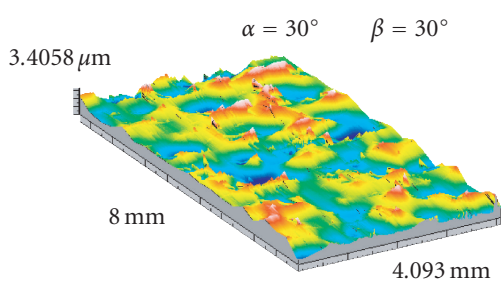

(a) Initial morphology of specimen

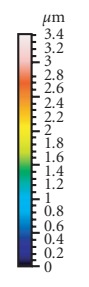

FIGURE 1: Morphology, its corresponding SEM of the initials

(a) $400 \mathrm{~mm} / \mathrm{min}$

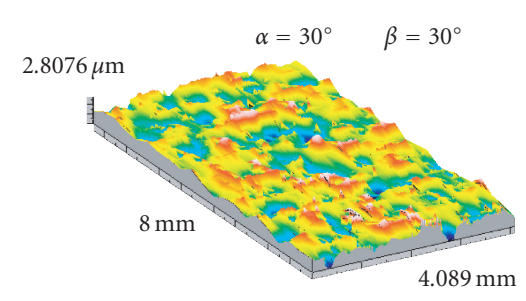

(c) $200 \mathrm{~mm} / \mathrm{min}$

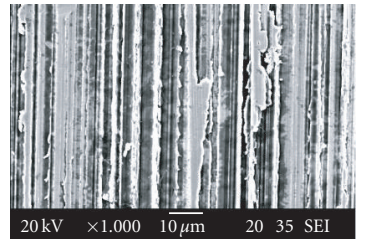

(b) SEM of the initial surface

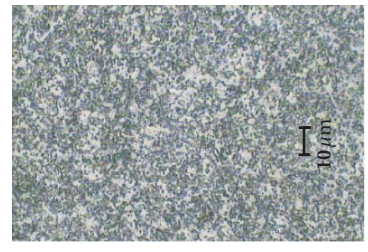

(c) Microstructure of DF2 steel

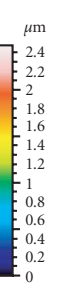

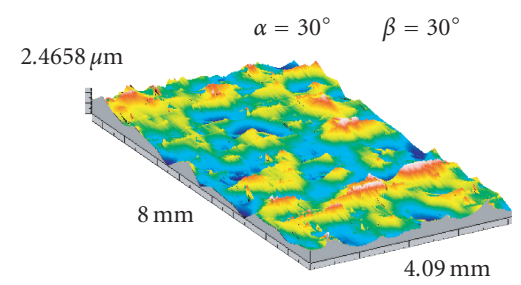

(b) $300 \mathrm{~mm} / \mathrm{min}$

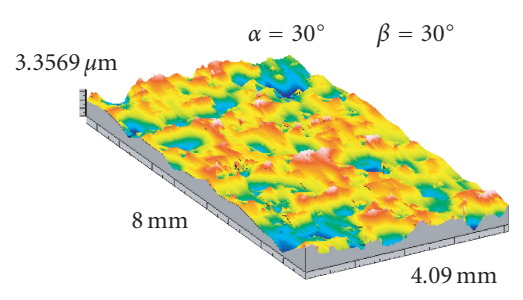

(d) $100 \mathrm{~mm} / \mathrm{min}$

Figure 2: Surface textures of laser polishing at various feedrates; $\mathrm{Ra}=0.4 \mu \mathrm{m}$, pulse energy $=1 \mathrm{~J}, f=25 \mathrm{~Hz}, \mathrm{PD}=3$ milliseconds.

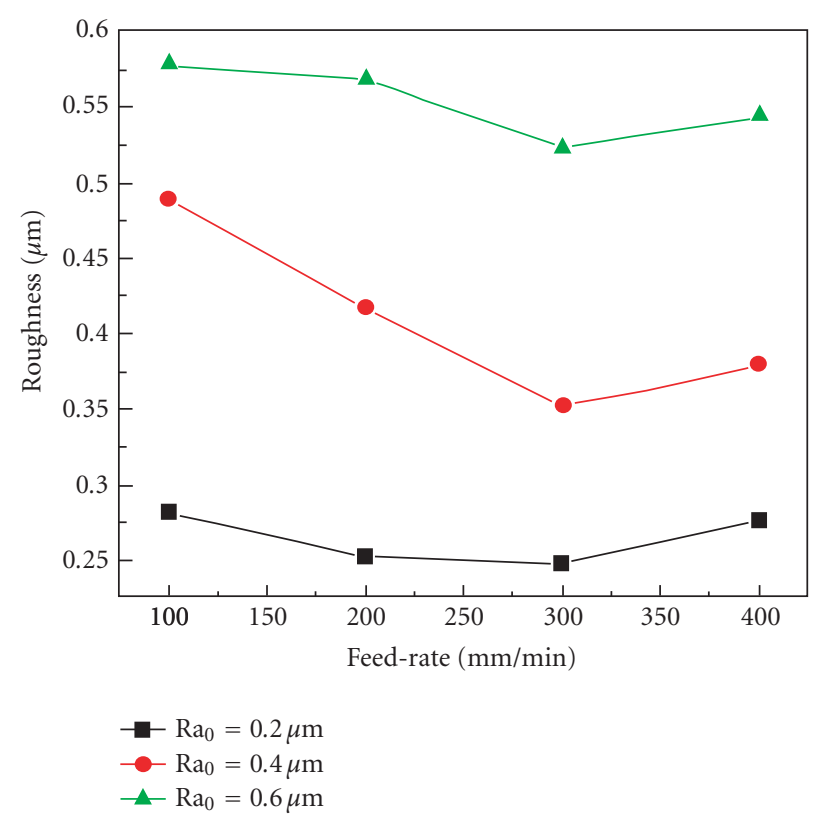

FIgUre 3: Relationship between Ra and feedrates.

(Figure 2) suggested that there was an optimal feedrate in achieving smoothest surface 3D morphology, which was at
$300 \mathrm{~mm} / \mathrm{min}$. The variation of morphology (Figure 2) illustrated that the smoother surface was obtained when feedrate increased from $100 \mathrm{~mm} / \mathrm{min}$ to $300 \mathrm{~mm} / \mathrm{min}$, and it became coarser once again when it was above $300 \mathrm{~mm} / \mathrm{min}$. When the feedrate was above $300 \mathrm{~mm} / \mathrm{min}$, increasing the magnitude of feedrate led to unsmooth surface. When feedrate was below $300 \mathrm{~mm} / \mathrm{min}$, increasing irradiation feedrate improved the surface morphology.

Figure 3 showed the relationship between the surface roughness $\mathrm{Ra}$ and the relative moving speed (feedrate) between the irradiating laser and the irradiated specimen. Results indicated that the initial increase in feedrate is accompanied with the decrease in surface roughness until the feedrate reached $300 \mathrm{~mm} / \mathrm{min}$ at which the surface roughness was the minimum. Then, further increase in the feedrate increased the roughness once again. Measurements illustrated that the surface roughness of irradiated specimens was to certain extent getting smoother along the irradiation path except with those specimens having surface roughness $\mathrm{Ra}=0.2 \mu \mathrm{m}$.

\subsection{Influence of laser irradiating pulse energy}

\subsubsection{Influence of laser irradiating pulse energy on surface morphology}

Figure 4 showed the effect of laser irradiating energy on surface morphology. Generally, increase in pulse energy 


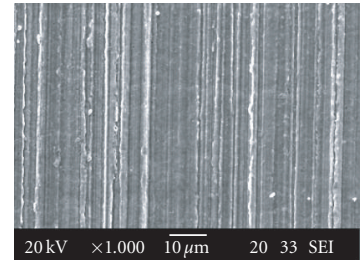

(a) Pulse energy $=2 \mathrm{~J}$

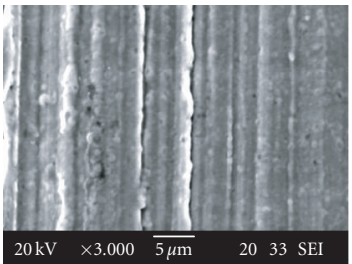

(b) Pulse energy $=2 \mathrm{~J}$

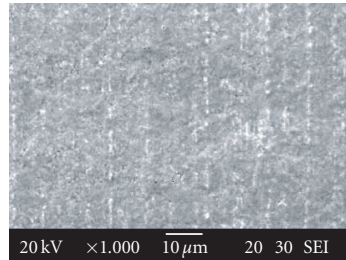

(c) Pulse energy $=3 \mathrm{~J}$

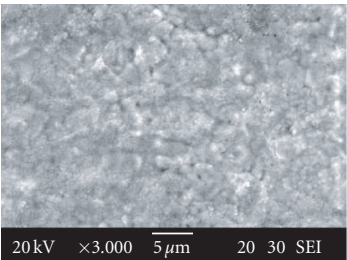

(d) Pulse energy $=3 \mathrm{~J}$

FIGURE 4: SEM of laser polishing surface morphologies at various pulse energies; $\mathrm{Ra}=0.4 \mu \mathrm{m}$, feedrate $=300 \mathrm{~mm} / \mathrm{min}, f=25 \mathrm{~Hz}, \mathrm{PD}=$ 3 milliseconds.

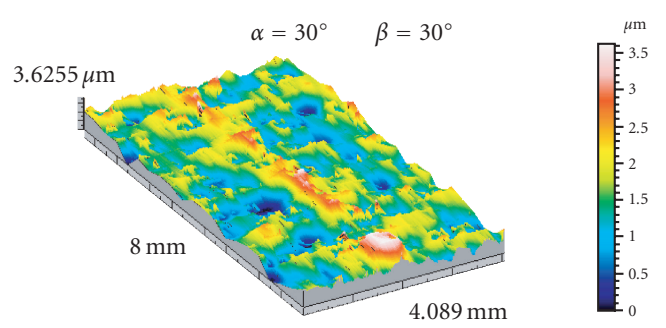

(a) Pulse energy $=2 \mathrm{~J}$

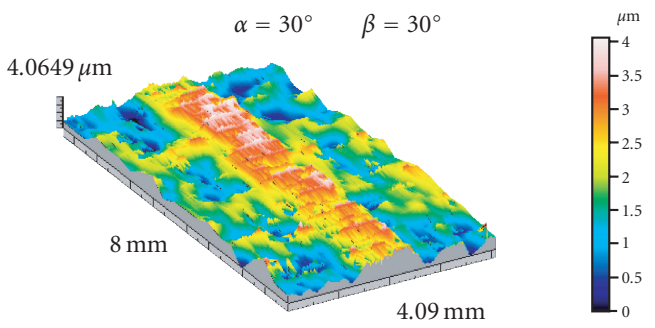

(b) Pulse energy $=3 \mathrm{~J}$

FIGURE 5: Surface textures of laser polishing at various pulse energies; $\mathrm{Ra}=0.4 \mu \mathrm{m}$, feedrate $=300 \mathrm{~mm} / \mathrm{min}, f=25 \mathrm{~Hz}$, PD $=3 \mathrm{milliseconds}$.

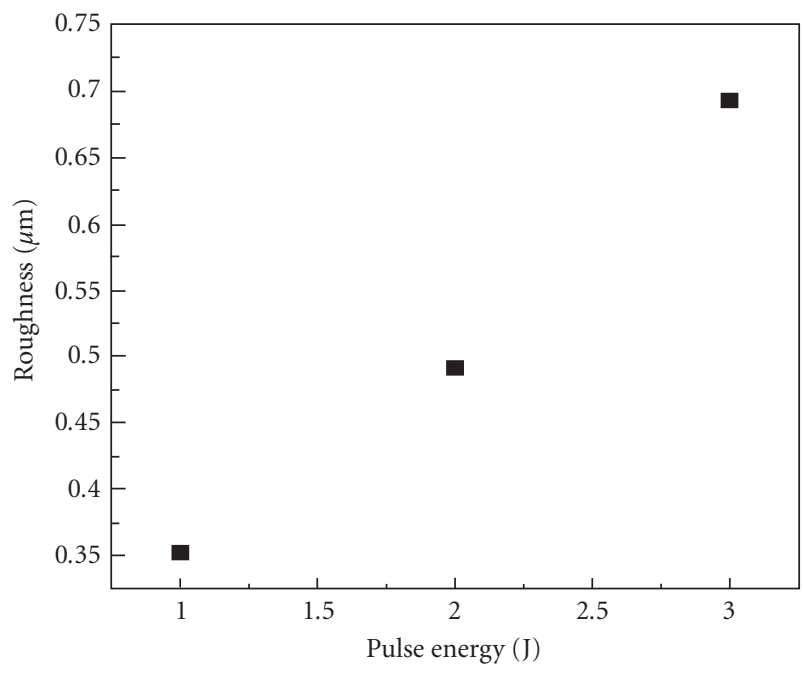

FIgURE 6: Relationship between Ra and pulse energy.

simultaneously raised up the heat input to the surface substrate. Too high pulse energy was likely to melt the surface of substrate which subsequently changed the surface morphology and mechanical properties of the DF2 steel specimens. When compared with the originally machined surface of $\mathrm{Ra}=0.4 \mu \mathrm{m}$ (Figure $1(\mathrm{~b})$ ), its treated surface (Figure 4(a)) irradiated under a feedrate $=300 \mathrm{~mm} / \mathrm{min}$, $f=25 \mathrm{~Hz}, \mathrm{PD}=3$ milliseconds and pulse energy $=2 \mathrm{~J}$ gave relatively smoother surface. However, its further magnified counterpart (Figure 4(b)) showed sign of some micro-pits and round agglomerates loosely scattering over both troughs and crests on the surface. Those round agglomerates would be the nucleus for re-solidifying the melt and subsequent shrinkage led to some locations slightly sinking below their surrounding material. Such surface morphology with scattering of micro-pits and microball-like features (Figure 4(b)) implied that there was some level of change of properties of DF2 surface. This change was not really anticipated since it was initially expected, from Figure 4(a), that the properties of the original surface morphology at pulse energy of $2 \mathrm{~J}$ would be the same as its as-received condition. At higher pulse energy (i.e., $3 \mathrm{~J}$ ), except those originally unmelted machining grooves forming small ridges (Figure 4(c)) scattering on the irradiated surface, relatively more severe melting and resolidification were observed. Such melting and resolidification (Figure $4(\mathrm{~d})$ ) were likely to change the properties of the initial surface drastically.

\subsubsection{Influence of laser pulse energy on surface roughness}

Figure 5 showed the textures of a surface irradiated at various pulse energies. Basically, the surface gradually became coarser when pulse energy was increasing. Figure 6 plotted the experimental data of the laser pulse energy and the irradiated surface roughness. It showed the surface roughness increased with the irradiated pulse energy. At pulse energy of $2 \mathrm{~J}$, the measured surface roughness was $0.49 \mu \mathrm{m}$ as a result of the appearance of those protrusions on the surface (see Figure 5(a)). The surface roughness approximately increased to $0.7 \mu \mathrm{m}$ when the pulse energy was increasing further because of the occurrence of more prominent protrusions on the irradiated surface. Furthermore, the width of the laserirradiated band became larger as observed in Figure 5(b), implying that laser polishing at pulse energy at and above $2 \mathrm{~J}$ under the setting conditions was generally not achievable. 


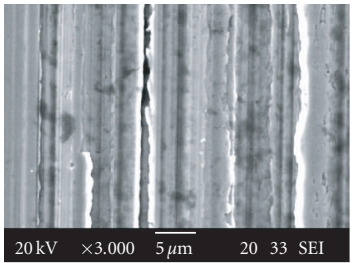

(a) $f=30 \mathrm{~Hz}$

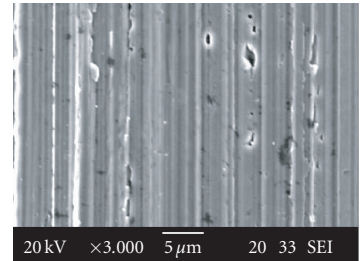

(b) $f=20 \mathrm{~Hz}$

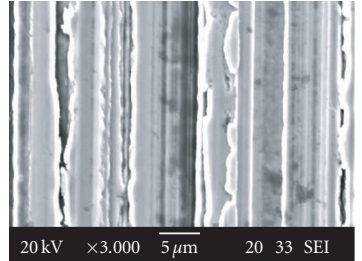

(c) $f=15 \mathrm{~Hz}$

FIGURE 7: SEM of laser polishing surface morphologies at various pulse frequencies; $\mathrm{Ra}=0.4 \mu \mathrm{m}$, pulse energy $=1 \mathrm{~J}$, feedrate $=300 \mathrm{~mm} / \mathrm{min}$, $\mathrm{PD}=3$ milliseconds.

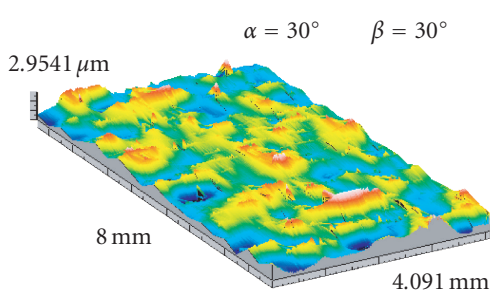

(a) $f=30 \mathrm{~Hz}$

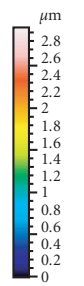

$\alpha=30^{\circ}$

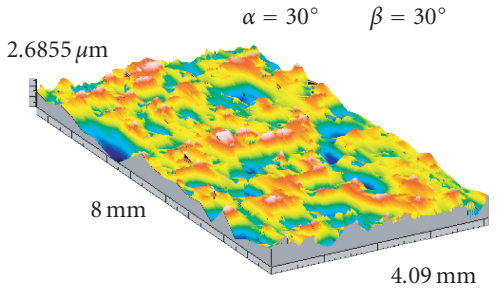

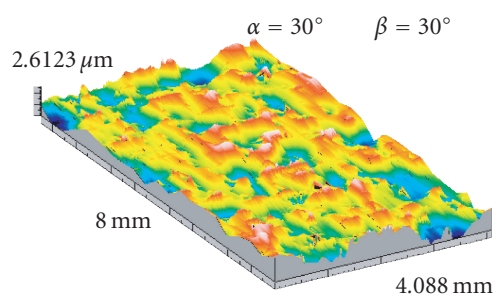

(b) $f=20 \mathrm{~Hz}$
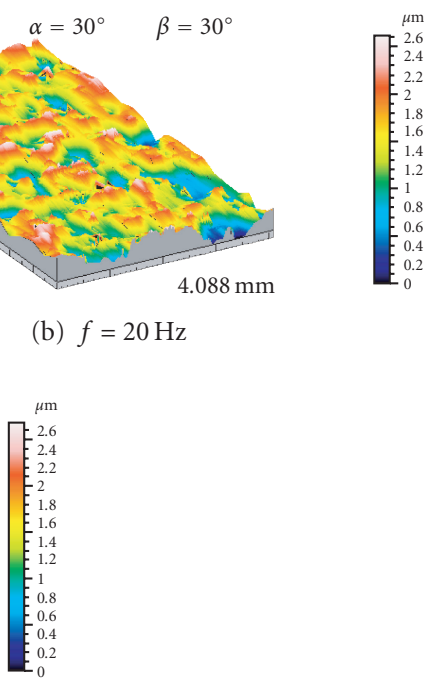

(c) $f=15 \mathrm{~Hz}$

FIGURE 8: Surface textures of laser polishing at various pulse frequencies; $\mathrm{Ra}=0.4 \mu \mathrm{m}$, pulse energy $=1 \mathrm{~J}$, feedrate $=300 \mathrm{~mm} / \mathrm{min}, \mathrm{PD}=$ 3 milliseconds.

\subsection{Influence of laser irradiation frequency (repetition rate)}

\subsubsection{Influence on surface morphology}

Result (Figure 7) showed that the increase in pulse frequency generally led the to making morphology of the irradiated surface smoother and smoother. But, the irradiated surface became coarser when the pulse frequency exceeded $25 \mathrm{~Hz}$, as shown in Figure 7(a).

\subsubsection{Influence on surface roughness}

Figure 8 showed the laser-irradiated surface scanned at various pulse frequencies. It showed that the roughness of the irradiated surface decreased with the pulse frequency when the pulse frequency was above $15 \mathrm{~Hz}$. At a pulse frequency of $30 \mathrm{~Hz}$, the increase in the roughness of the irradiated surface resulted in a coarser irradiated surface.

Figure 9 showed the corresponding relationship between the pulse frequency and the irradiated roughness. It illustrated that the roughness of the irradiated surface was below $0.4 \mu \mathrm{m}$ when the pulse frequency was in the range of $20 \mathrm{~Hz}$ to $25 \mathrm{~Hz}$, which gave the minimum value of roughness value.

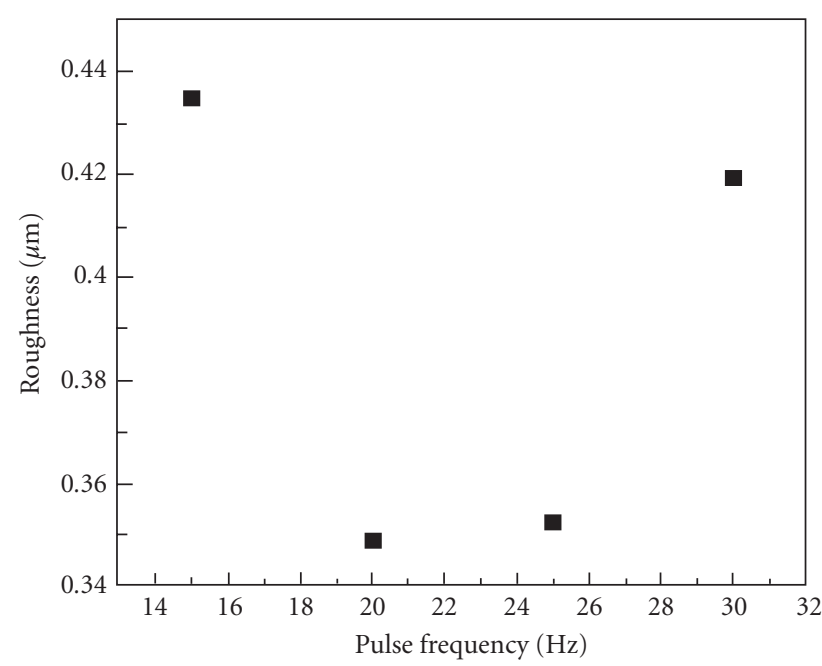

FIGURE 9: Relationship between Ra and pulse frequencies.

When the pulse frequency was above $25 \mathrm{~Hz}$, the roughness of the irradiated surface was increasing again, implying that the irradiated surface became coarser when the pulse frequency was either below $20 \mathrm{~Hz}$ or above $25 \mathrm{~Hz}$. 


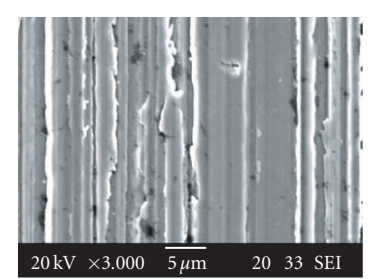

(a) $\mathrm{PD}=2 \mathrm{~ms}$

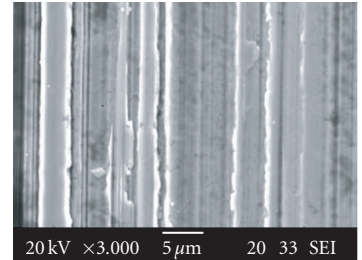

(b) $\mathrm{PD}=3 \mathrm{~ms}$

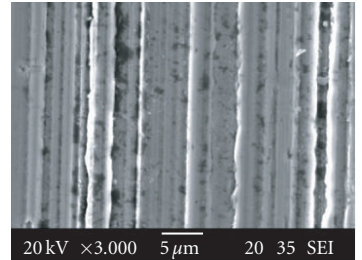

(c) $\mathrm{PD}=4 \mathrm{~ms}$

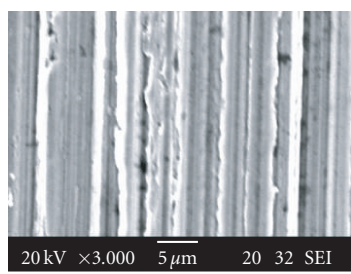

(d) $\mathrm{PD}=5 \mathrm{~ms}$

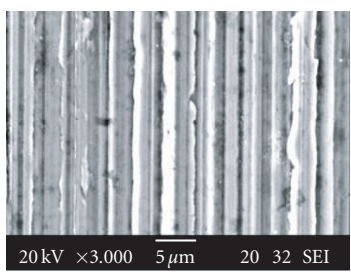

(e) $\mathrm{PD}=6 \mathrm{~ms}$

FIGURE 10: SEM of laser polishing surface morphologies at various pulse durations; $\mathrm{Ra}=0.4 \mu \mathrm{m}$, pulse energy $=1 \mathrm{~J}$, feedrate $=300 \mathrm{~mm} / \mathrm{min}$, $f=20 \mathrm{~Hz}$.

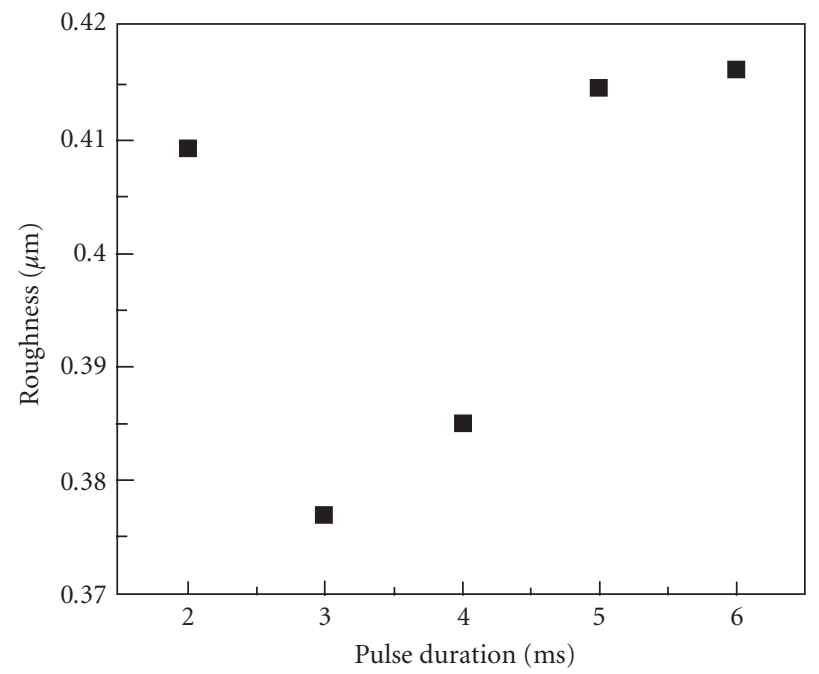

FIgURE 11: Relationship between Ra and pulse duration.

\subsection{Influence of laser polishing pulse duration (PD)}

\subsubsection{Influence on surface morphology}

Figure 10 illustrated the influence of pulse duration on the polished surface roughness and morphology. It was observed that the DF2 surface was polished effectively when the pulse duration was in the range of 3 milliseconds to 4 milliseconds. With longer pulse duration, some level of microscale melted ridges was seen (Figures 10(d) and 10(e)).

\subsubsection{Influence on surface roughness}

Figure 11 showed the relationship of the measured roughness and pulse duration. It showed that the decrease in pulse duration reduced the roughness of the irradiated surface correspondingly. At the pulse duration of 3 milliseconds, the irradiated surface roughness among the tests reached its minimum value. When the pulse duration was lower than 3 milliseconds, the roughness of irradiated surface started to increase again to some respective level. It was observed that the irradiated surface became rougher at longer pulse duration of 4, 5, 6 milliseconds and typically illustrated the effect of longer pulse duration on the irradiated surface.

\section{CONCLUSIONS}

Successful polishing DF2 cold work steel was achievable by a $\mathrm{Nd}$ :YAG laser with the irradiating parameters set as $\mathrm{P}=1 \mathrm{~J}$, feedrate $=300 \mathrm{~mm} / \mathrm{min}, \mathrm{PD}=3 \mathrm{~ms}, f=20 \sim 25 \mathrm{~Hz}$.

\section{ACKNOWLEDGMENT}

This work was supported by a grant from the Research Grants Council of Hong Kong SAR [Project No. CityU $1175 / 03 \mathrm{E}]$.

\section{REFERENCES}

[1] W. M. Steen, Laser Material Processing, Springer, London, UK, 3rd edition, 2003.

[2] K. Steinhoff, W. Rasp, and O. Pawelski, "Formation of paint surface on different surface structure of steel sheet," Iron and Steel Engineer, vol. 74, no. 3, pp. 43-49, 1997.

[3] W. W. Duley, Laser Processing and Analysis of Materials, Plenum Press, New York, NY, USA, 1983.

[4] G. Ryk, Y. Kligerman, I. Etsion, and R. Ryason, "Experimental investigation of laser surface texturing for reciprocating automotive components," Tribology Transactions, vol. 45, no. 4, pp. 444-449, 2002.

[5] S. Lugomer, Laser Technology: Laser Driven Processes, PrenticeHall, Englewood Cliffs, NJ, USA, 1990. 

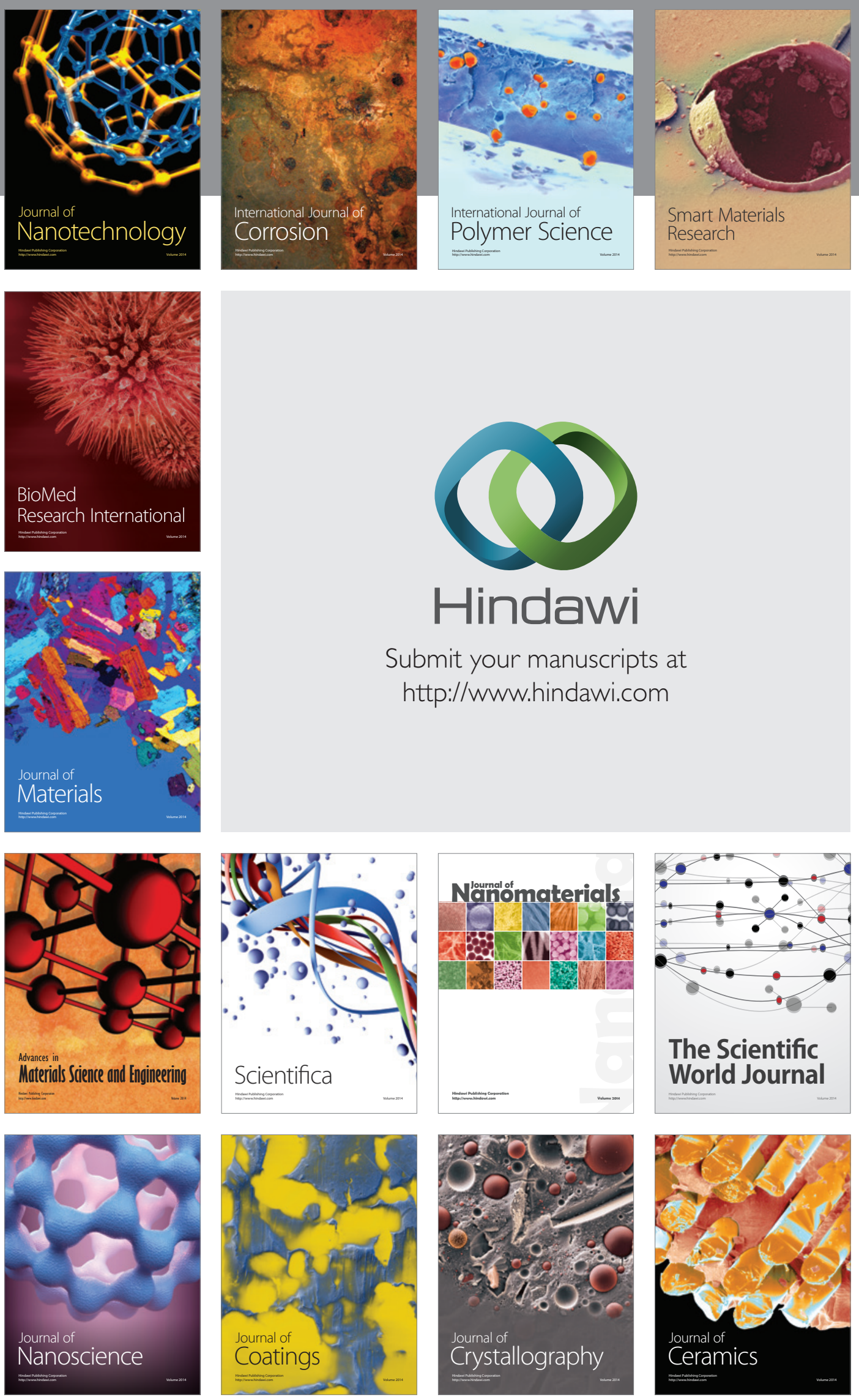

The Scientific World Journal

Submit your manuscripts at

http://www.hindawi.com

\section{World Journal}

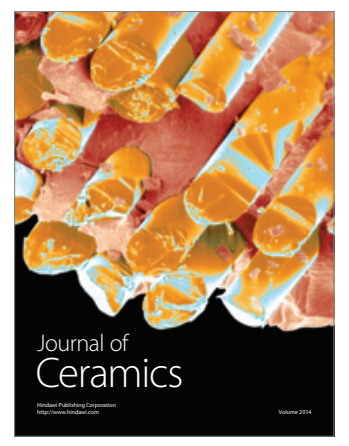

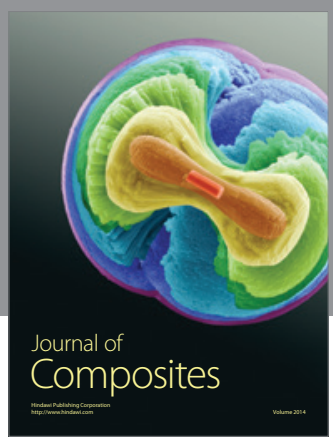
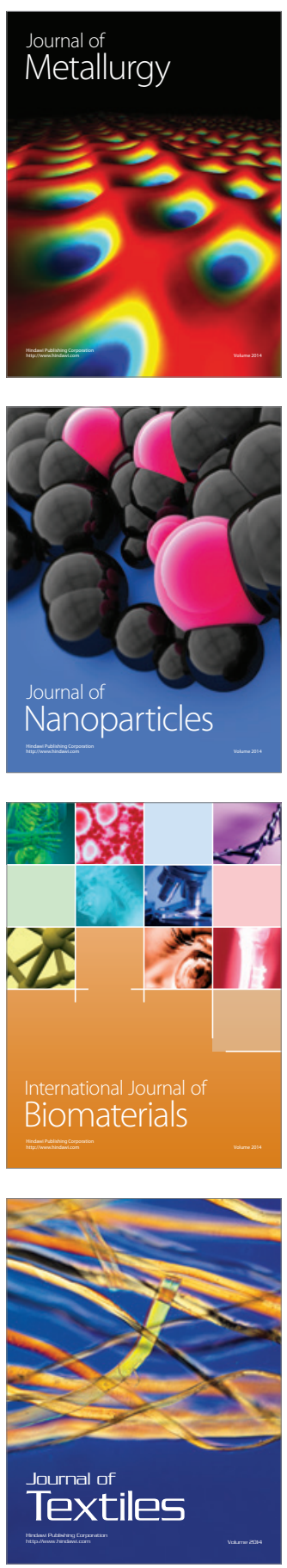